\title{
ALADPA : Snake in the Heart
}

\author{
Suresh Madhavan ${ }^{1}$, Gargi Sathish ${ }^{2}$, Jayaprasad N¹. \\ ${ }^{1}$ Department of Cardiology Government Medical College, Kottayam, Kerala, India \\ ${ }^{2}$ Department of Opthalmology Government Medical College, Kottayam, Kerala, India
}

\section{Citation}

Suresh Madhavan, Gargi Sathish, Jayaprasad N.. ALADPA: Snake in the Heart. Nepalese Heart Journal 2015; 12 (1) 27-30

Key words

coronary anomalies, ALCAPA, ALADPA

\section{ABSTRACT}

Anomalous origin of left coronary artery from pulmonary artery may or may not be associated with structural heart disease. Most of the patients with such coronary anomaly will succumb unless diagnosed and treated early. We are reporting a patient with this anomaly in seventh decade which is extremely rare.

\section{INTRODUCTION}

Anomalous origin of left coronary artery from pulmonary artery [ALCAPA] is a rare congenital coronary anomaly usually detected during infancy or childhood. Anomalous origin of left anterior descending coronary artery from pulmonary artery [ALADPA] is extremely rare and usually it is a postmortem diagnosis. Patients surviving up to old age with ALADPA is not reported.

\section{CASE REPORT}

A 65 year old male, heavy manual labourer with no conventional risk factors was referred for evaluation of continuous murmur in the precordium while admitted for cataract surgery. His vital signs were normal. Precordial examination revealed faint continuous murmur in the second left intercostal space close to the sternum. ECG and chest X-ray were normal. Echocardiography showed normal cardiac valves and cardiac chambers with normal biventricular function and no regional wall motion abnormality. Parasternal long axis view showed dilated right coronary artery measuring $7 \mathrm{~mm}$ in diameter [figure 1a]. On tilting the echo probe anteriorly in apical 4-chamber view a serpentine vessel at the level of inter ventricular septum with clearly demonstrable flow [figure $1 \mathrm{~b}$ and $1 \mathrm{c}$ ] was observed. Coronary angiogram revealed origin of left circumflex artery from left sinus [figure 1d and 1e]. Right coronary artery was dilated and tortuous. The left anterior descending artery was dilated and had a serpentine course, filling from right coronary artery via collaterals and draining to pulmonary artery suggestive of ALADPA [figure 1f]. Patient was not keen for corrective surgery. He underwent uneventful cataract surgery and patient is on follow up. Among the anomalous origin of coronary arteries from pulmonary trunk,origin of Left anterior descending artery from pulmonary artery is extremely rare and usually it is a postmortem diagnosis. We are reporting the case as unusual presentation as the patient had no evidence of ischemia even at the age of 65 years and clear delineation of the serpentine Anomalous Left Anterior Descending artery from echocardiography itself.

\section{DISCUSSION}

\section{Corresponding Author}

\section{Suresh Madhavan}

Department of Cardiology

Government Medical College,

Kottayam, Kerala, India 686008

Email: drsureshmadhavan76@gmail.com 

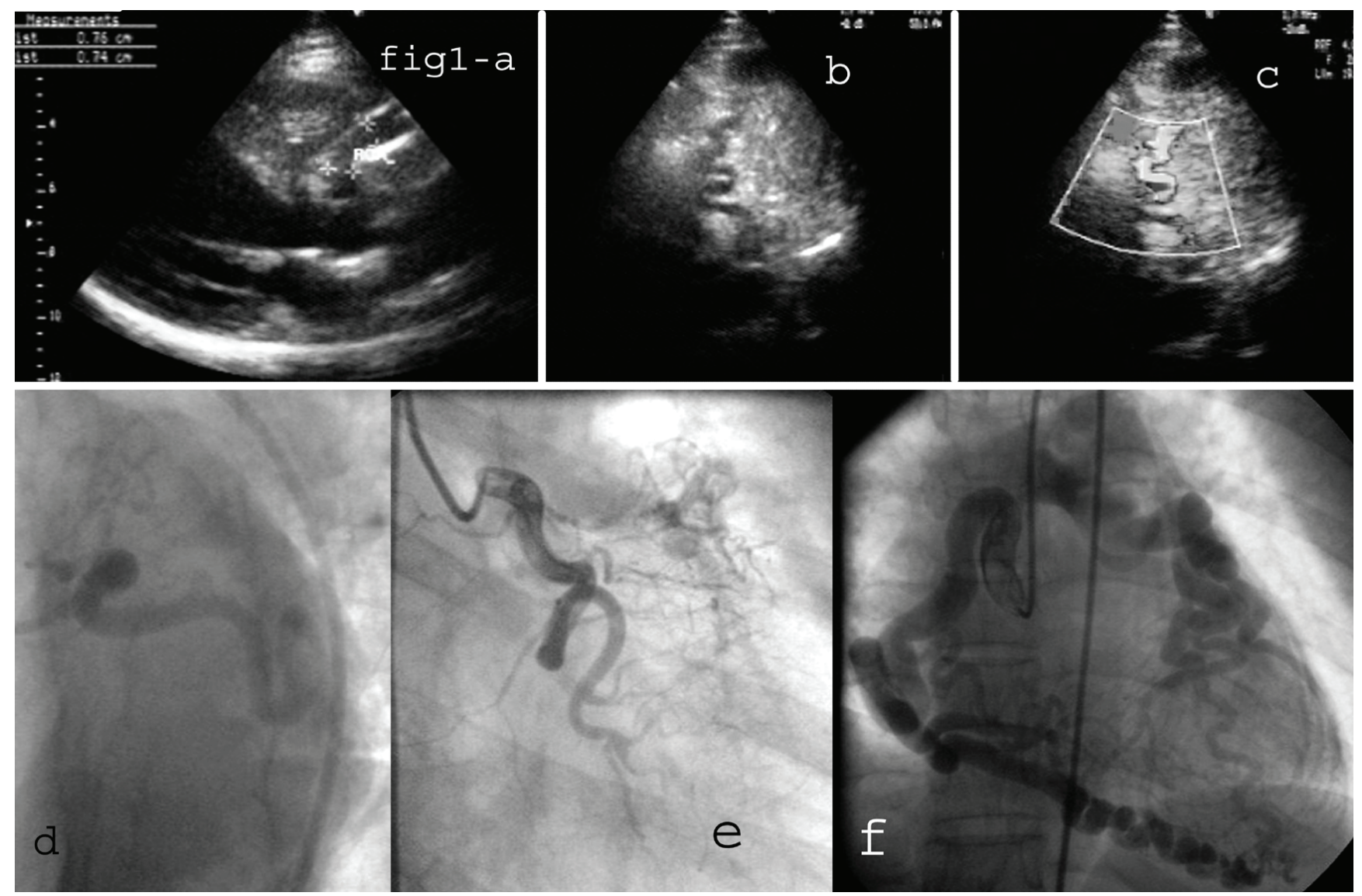

Anomalous origin of left coronary artery from pulmonary artery [ALCAPA] is a rare congenital coronary anomaly, in which the left coronary artery arises from the pulmonary artery usually from the left posterior facing sinus. Among the ALCAPAs, isolated origin of left anterior descending artery from the pulmonary artery [ALADPA] is extremely rare. In fetal life, since both pulmonary artery and coronary arteries are having same pressures and saturation this anomaly has no harmful effect. After birth, the LAD territory with its huge demand for oxygen, is perfused with desaturated blood from pulmonary artery at low pressures. Collateral flow from Right coronary artery [RCA] is initially low. In order to improve coronary flow, the vessels get dilated and vascular resistance falls. Once the coronary vascular reserve exhausts ischemia ensues. ${ }^{2}$ Collaterals from the RCA enlarges over time, finally the blood from RCA is shunted to the pulmonary artery via LAD. This left to right shunt is large in terms of coronary flow. Usually patients with ALADPA become symptomatic during first year of life itself except when there is extensive collaterals from RCA and associated obstructive opening at the origin of LAD. ${ }^{3}$ Clinical findings of mitral regurgitation, left ventricular failure, pulmonary hypertension, right ventricular failure may ensue with progression of disease. Classically there is a finding of anterolateral myocardial infarction in electrocardiogram at the time of diagnosis. Even in asymptomatic adults, the resting electrocardiogram is abnormal, and abnormal ischemic responses occur with exercise. ${ }^{4,5,6}$ On the chest film in affected infants there is marked cardiomegaly, predominantly of the left atrium and ventricle, and evidence of pulmonary edema. These features are similar to those of many forms of cardiomyopathy, with which this anomaly is often confused. Echocardiography with Doppler color flow mapping gives adequate clues towards diagnosis. Dilated right coronary artery is a hint towards ALCAPA. Presence of 
diastolic flow in the pulmonary artery, regional wall motion abnormality of LAD territory, mitral regurgitation, increased echogenicity of the papillary muscle and adjacent endocardium due to fibrosis and fibroelastosis are additional clues to the echo diagnosis of ALADPA. ${ }^{7}$ If the results of noninvasive imaging points towards suspected ALADPA, then coronary angiography, Cardiac MRI and cardiac CT-scans can definitely help in anatomical delineation of the anomaly. ${ }^{8,9}$ Treatment includes medical stabilization followed by definitive repair of the abnormal anatomy. Various surgical techniques have been defined for the definitive repair of ALCAPA like ligation of the origin of the left coronary artery and reconstitution of flow through it with a subclavian arterial, internal mammary arterial or saphenous venous grafts, direct reimplantation of the origin of the LAD into the aorta, Takeuchi procedurein which an aortopulmonary window is created and then a tunnel fashioned that directs blood from the aorta to the left coronary ostiumetc. However in ALADPA, there are not much of modalities reported. ${ }^{10-13}$ Ligation of the anomalous artery or connecting it to the aorta has been recommended. ${ }^{14}$ Early surgical intervention has been found to have significantly improved outcomes. However, because of papillary muscle infarction and dysfunction, significant preoperative mitral insufficiency has been found to be a risk factor for both mortality and need for late mitral valve surgery. It has been reported that surgery is feasible even in the sickest infants if postoperative support with a left ventricular assist device is used. ${ }^{15}$ 


\section{REFERENCES}

1. DerrickM.J,Moreno Cabral :Anomalous origin of the left anterior descending artery from the pulmonary artery .J cardiac surg 6:24,1991

2. Wesselhoeft H, Fawcett JS, Johnson AL. Anomalous origin of the left coronary artery from the pulmonary trunk. Its clinical spectrum, pathology, and pathophysiology, based on a review of 140 cases with seven further cases. Circulation 1968;38:403-425.

3. Click RL, Holmes DR Jr, Vlietstra RE, et al. Anomalous coronary arteries: Location, degree of atherosclerosis and effect on survival "a report from the Coronary Artery Surgery Study. J Am CollCardiol 1989;13:531-537.

4. Chang RR, Allada V. Electrocardiographic and echocardiographic features that distinguish anomalous origin of the left coronary artery from pulmonary artery from idiopathic dilated cardiomyopathy. PediatrCardiol 2001.

5. Bland EF, White PD, Garland J. Congenital anomalies of the coronary arteries: Report of an unusual case associated with cardiac hypertrophy. Am Heart J 1933;8:787-801.

6. Roberts WC. Major anomalies of coronary arterial origin seen in adulthood. Am Heart J 1986;111:941-963.

7. Dawn B, Talley JD, Prince CR, et al. Two-dimensional and Doppler transesophageal echocardiographic delineation and flow characterization of anomalous coronary arteries in adults. J Am SocEchocardiogr 2003;16:1274-1286.

8. Casolo G, Del Meglio J, Rega L, et al. Detection and assessment of coronary artery anomalies by three-dimensional magnetic resonance coronary angiography. Int J Cardiol 2005;103:317322 .

9. Schmitt R, Froehner S, Brunn J, et al. Congenital anomalies of the coronary arteries: Imaging with contrast-enhanced, multidetector computed tomography. EurRadiol 2005;15:1110-1121.

10. Moodie DS, Fyfe D, Gill CC, et al. Anomalous origin of the left coronary artery from the pulmonary artery (Bland-White-Garland syndrome) in adult patients: Long-term follow-up after surgery. Am Heart J 1983;106:381-388.

11. Liebman J, Hellerstein HK, Ankeney JL, et al. The problem of the anomalous left coronary artery arising from the pulmonary artery in older children. Report of three cases. N Engl J Med 1963;269:486-494.

12. Shrivastava S, Casteneda AR, Moller JH. Anomalous left coronary artery from pulmonary trunk. Long-term follow-up after ligation. J ThoracCardiovascSurg 1978;76:130-134.

13. Takeuchi S, Imamura H, Katsumoto et al. new surgical method for repair of anomalous left coronary artery from pulmonary artery. J ThoracCardiovascSurg 1979;78:7-11

14. Matherne GP, Lim DS. Congenital Anomalies of the Coronary Vessels and the Aortic Root. In: Allen HD, Driscoll, DJ, Shaddy, RE, Feltes TF, editors. Moss and Adams' Heart Disease in Infants, Children, and Adolescents: Including the Fetus and Young Adults, 7th Edition. Philadelphia: Lippincott Williams \& Wilkins; 2008.

15. Del Nido PJ, Duncan BW, Mayer JE Jr, et al. Left ventricular assist device improves survival in children with left ventricular dysfunction after repair of anomalous origin of the left coronary artery from the pulmonary artery. Ann ThoracSurg 1999;67:169-172. 